\title{
Mucosal immunology of geohelminth infections in humans
}

\author{
PJ Cooper ${ }^{1,2,3}$
}

There is limited data on the human mucosal immune response to geohelminths, but extensive data from experimental animals. Geohelminth infections may modulate mucosal immunity with effects on parasite expulsion or persistence and mucosal inflammation. Geohelminths are considered to have important effects on immunity to mucosal vaccines, infectious disease susceptibility, and anti-inflammatory effects in inflammatory bowel disease and asthma. This review will discuss the findings of studies of human immunity to geohelminths and their potential effects on non-parasite mucosal immune responses. Such effects are likely to be of public health importance in middle- and low-income countries where these parasites are endemic. There is a need for human studies on the effects of geohelminth infections on mucosal immunity and the potential for anthelmintic treatment to modify these effects. Such studies are likely to provide important insights into the regulation of mucosal immunity and inflammation, and the development of more effective mucosal vaccines.

\section{INTRODUCTION}

Geohelminth (also known as intestinal helminths and soiltransmitted helminths) infections are caused by Ascaris lumbricoides, Trichuris trichiura, hookworm (Ancylostoma duodenale and Necator americanus), and Strongyloides stercoralis and are estimated to infect greater than 2 billion humans worldwide. ${ }^{1}$ Several other less-common helminth infections may have important effects on mucosal immunity (Table 1), but these will not be considered further here.

Geohelminth infections are most prevalent among poor populations living in warm, moist climates in tropical and subtropical regions of low- and middle-income countries (LMICs), where access to sanitation and clean water is limited. Infections are acquired by ingestion of fecally contaminated food and water or direct contact with contaminated soil. Individuals living in endemic areas are commonly infected with more than one geohelminth parasite, and infections are generally acquired after 9 months of age and may persist into adulthood through repeated infectious exposures.

The epidemiology of geohelminth infections in endemic areas is likely to have been influenced by two factors: (1) the process of urbanization in which increasingly greater proportions of the population are living in urban or urbanized environments, where the transmission of infections is localized to areas without sanitary infrastructure; and (2) anthelmintic treatment programs using periodic treatments targeted at school-age children, the major reservoir of infection in endemic communities, have been implemented in many LMICs. Geohelminth infections are relatively rare in high-income countries (HICs) such as the United Kingdom, where the few reported infections are detected in migrants or long-term travelers to endemic areas. ${ }^{2}$

\section{DISEASE CAUSED BY GEOHELMINTHS}

Geohelminth infections are associated with significant morbidity and mortality among children. The morbidity caused by geohelminth infections is strongly associated with infection intensity and may include anemia, ${ }^{3,4}$ growth retardation, ${ }^{5,6}$ and cognitive impairment. A recent meta-analysis of randomized intervention studies indicated that anthelmintic treatment of school-age children might improve weight but not linear growth. ${ }^{7}$ These effects were observed after single doses of anthelmintic drugs and further treatment doses did not appear to provide additional benefits. ${ }^{7}$ There is limited evidence that anthelmintic treatment improves cognition or educational achievement. ${ }^{7,8}$ Recent randomized studies have provided evidence that preschool children who harbor low parasite burdens may benefit from anthelmintic treatment with increases in weight. ${ }^{9,10}$ The mechanisms by which geohelminths affect ponderal growth may include alterations in the absorptive capacity of the intestinal mucosa and the cachectic effects of pro-inflammatory cytokines (e.g., tumor

\footnotetext{
${ }^{1}$ Laboratorio de Investigaciones FEPIS, Quinindé, Esmeraldas Province, Ecuador. ${ }^{2}$ Instituto de Microbiologia, Universidad San Francisco de Quito, Quito, Ecuador. ${ }^{3}$ Centre for Infection, Department of Cellular and Molecular Medicine, St George's University of London, London, UK. Correspondence: PJ Cooper (pcooper@ecnet.ec) 
Table 1 Human helminth infections found at mucosal sites and important effects on mucosal immunity and disease

\begin{tabular}{|c|c|c|c|}
\hline Helminths & Tissue site & Pathology & $\begin{array}{l}\text { Therapeutic } \\
\text { effect }\end{array}$ \\
\hline \multicolumn{4}{|l|}{ Natural infections } \\
\hline $\begin{array}{l}\text { Ascaris } \\
\text { lumbricoides }\end{array}$ & $\begin{array}{l}\text { Small } \\
\text { intestine }\end{array}$ & $\begin{array}{l}\text { Asthma/ } \\
\text { enteropathy }\end{array}$ & No \\
\hline $\begin{array}{l}\text { Trichuris } \\
\text { trichiura }\end{array}$ & $\begin{array}{l}\text { Large } \\
\text { intestine }\end{array}$ & TDS/colitis & No \\
\hline Hookworm & $\begin{array}{l}\text { Small } \\
\text { intestine }\end{array}$ & Enteropathy & $\begin{array}{l}\text { Asthma/ } \\
\text { Crohn's } \\
\text { disease }\end{array}$ \\
\hline $\begin{array}{l}\text { Strongyloides } \\
\text { stercoralis }\end{array}$ & $\begin{array}{l}\text { Small } \\
\text { intestine }\end{array}$ & Enteropathy & No \\
\hline $\begin{array}{l}\text { Wuchereria } \\
\text { bancrofti }\end{array}$ & Lymphatics & TPE & No \\
\hline $\begin{array}{l}\text { Paragonimus } \\
\text { spp }\end{array}$ & $\begin{array}{l}\text { Lung } \\
\text { parenchyma }\end{array}$ & Asthma & No \\
\hline $\begin{array}{l}\text { Schistosoma } \\
\text { mansoni }\end{array}$ & $\begin{array}{l}\text { Mesenteric } \\
\text { veins }\end{array}$ & Enteropathy & No \\
\hline $\begin{array}{l}\text { Schistosoma } \\
\text { haematobium }\end{array}$ & $\begin{array}{l}\text { Vesical } \\
\text { plexus }\end{array}$ & $\begin{array}{l}\text { Urinary tract } \\
\text { pathology }\end{array}$ & No \\
\hline $\begin{array}{l}\text { Schistosoma } \\
\text { japonicum }\end{array}$ & $\begin{array}{l}\text { Mesenteric } \\
\text { veins }\end{array}$ & Enteropathy & No \\
\hline $\begin{array}{l}\text { Fasciolopsis } \\
\text { buski }\end{array}$ & $\begin{array}{l}\text { Small } \\
\text { intestine }\end{array}$ & $\begin{array}{l}\text { Intestinal } \\
\text { ulceration }\end{array}$ & No \\
\hline \multicolumn{4}{|c|}{ Zoonotic infections } \\
\hline Trichuris suis & $\begin{array}{l}\text { Large } \\
\text { intestine }\end{array}$ & Asymptomatic & $\begin{array}{l}\text { Crohn's } \\
\text { disease/ } \\
\text { ulcerative } \\
\text { colitis }\end{array}$ \\
\hline Ascaris suis & $\begin{array}{l}\text { Lungs/ } \\
\text { intestine }\end{array}$ & Asthma & No \\
\hline Toxocara spp & Tissues & Asthma & No \\
\hline $\begin{array}{l}\text { Ancylostoma } \\
\text { caninum }\end{array}$ & $\begin{array}{l}\text { Small } \\
\text { intestine }\end{array}$ & Enteropathy & No \\
\hline
\end{tabular}

TDS, Trichuris dysentery syndrome; TPE, tropical pulmonary eosinophilia.

necrosis factor- $\alpha$, TNF- $\alpha$ ) arising from mucosal inflammation. Intestinal helminths impair epithelial barrier function causing increased mucosal permeability and intraluminal fluid accumulation, ${ }^{11}$ and such effects have been attributed to the upregulation of T helper cell type 2 (Th2) cytokines. ${ }^{12}$

\section{HUMAN IMMUNE RESPONSE TO GEOHELMINTH INFECTIONS}

Systemic immunity

The human immune response to helminth infections is associated with increased levels of IgE, tissue eosinophilia, and mastocytosis, and the presence of CD4 + T cells that preferentially produce interleukin (IL)-4, IL-5, and IL-13. ${ }^{13-15}$ The development of protective immunity to intestinal helminths in experimental animals is dependent on the development of CD4+ Th2-type cytokine responses. ${ }^{16}$
Human studies have shown that resistance to infection may be associated with the production of Th2 cytokines by peripheral blood leukocytes (PBLs): in the case of A. lumbricoides and T. trichiura infections, increasing levels of Th2 cytokines were associated with an age-dependent reduction in infection intensity, ${ }^{17}$ and increased susceptibility to re-infection was associated with weak Th2 cytokine responses; ${ }^{15}$ in the case of hookworm infection, a study of infected adults from a highly endemic area of Papua New Guinea showed an association between levels of IL-5 and resistance to re-infection after treatment. ${ }^{18}$

Th2 cytokines activate multiple effector mechanisms that may kill or expel geohelminth parasites and include the infiltration of mucosa with inflammatory cells, including Th2 CD4 + T cells, eosinophils, mast cells primed with specific IgE, increased smooth muscle contractility, epithelial cell turnover, and mucus secretion. ${ }^{16,19}$ Intestinal helminth parasites induce a generic Th2 immune response in infected hosts, ${ }^{16,19}$ and the specific mechanisms that mediate protective immunity vary between different geohelminth parasites and parasite life-cycle stages.

Studies of mucosal immunity in humans. Geohelminth parasites have intimate contact with the mucosal immune system being separated from the intestinal tissues by a single layer of epithelium. Although there are extremely detailed data of the mucosal immune response to intestinal helminth infections of animals, data of mucosal immune responses to geohelminths in humans are very limited. Major limitations for human studies are ethical and technical restrictions in sampling of mucosal sites in asymptomatic children living among populations with very limited access to health facilities. Most published studies have inferred immunological mechanisms by sampling of peripheral blood, ${ }^{15,17,20}$ feces, ${ }^{21}$ or saliva. ${ }^{22}$ Studies using peripheral blood after mucosal vaccination can sample B cells ${ }^{23}$ and $\mathrm{T}$ cells $\mathrm{s}^{24-26}$ trafficking between mucosal sites. ${ }^{27}$ Therapeutic studies of geohelminth infections in the treatment of inflammatory diseases in adults in HICs should provide new opportunities for the study of mucosal immunity during geohelminth infections by routine endoscopy and new diagnostic tools, such as wireless endoscopy, that permit sampling throughout the intestinal tract.

Changes in the intestinal mucosa associated with geohelminth infections. The expulsion of intestinal helminth parasites in animal models has been associated with marked changes in the intestinal mucosa characterized by villous atrophy, crypt hypertrophy, and increases in mucous-secreting goblet cells. ${ }^{16,19,28}$ The intestinal epithelium proliferates so that parasites that live partly or completely in the epithelium (e.g., Trichinella spiralis and Trichuris spp.) are shed into the gut-the epithelial escalator. ${ }^{11}$ These changes may make the luminal environment more hostile and reduce the surface area for parasite attachment. Both parasite expulsion and intestinal enteropathy are Th2dependent. ${ }^{28,29}$

Few studies have described the histological appearance of the human intestinal tract during helminth infections, which are summarized below:

(1) A. lumbricoides-The life cycle of A. lumbricoides includes a stage of larval migration through the lungs before the juvenile 
worms reach the small intestine and develop into adults. The migration of larvae through the lungs has been associated with the development of a transient asthma-like syndrome (Loeffler's syndrome, pulmonary ascariasis, or eosinophilic pneumonitis) characterized by strong allergic-type reactions directed against migrating larvae that become trapped in eosinophil-rich granulomas in the lung. ${ }^{30}$ Pulmonary ascariasis may be most severe after previous episodes of sensitization in areas where infection is transmitted seasonally, ${ }^{31}$ and appears to be rare in areas where transmission occurs throughout the year. ${ }^{32}$ There is little or no data on the human mucosal response to adult A. lumbricoides worms in the intestinal tract during uncomplicated infections. Studies of natural infections with Ascaris suis in pigs have shown an unremarkable mucosal reaction to the presence of adult worms characterized by little or no change in the numbers of eosinophils and mast cells, ${ }^{33}$ but increased IgA and IgM plasma cells in the jejunal mucosa. ${ }^{34}$

(2) T. trichiura-After ingestion of infective eggs, the infective larvae of $T$. trichiura are believed to hatch in the jejunum and within a week migrate to the cecum, where the adults bury their heads in the epithelium. ${ }^{35}$ Adult worms may extend from the cecum to the rectum during heavy infections. Lightly infected children are generally asymptomatic, ${ }^{36}$ but heavy infections may be associated with colitis ${ }^{36}$ or rarely a dysentery-like syndrome (Trichuris dysentery syndrome or TDS) ${ }^{37}$ Little is known about the human response to initial infections with $T$. trichiura. Histological examination of the small bowel during chronic infections with T. trichiura is generally normal. Colonic biopsies of children with chronic trichuriasis were indistinguishable from local controls except in the region of the worm head where the epithelium was flattened. ${ }^{38}$ Comparisons of colonic biopsy samples between infected children and local controls showed a mild to moderate inflammatory infiltrate in the lamina propria in both groups, and similar numbers of lamina propria CD 3 + and CD8 + T cells and levels of epithelial MHC class II expression..$^{38}$ However, increased numbers of IgM plasma cells and reduced numbers of intraepithelial $\mathrm{T}$ cells were observed in infected children. ${ }^{38} \mathrm{~A}$ study comparing rectal biopsy samples between children with TDS and local controls showed that children with TDS had significantly greater number of IgE + mast cells in the sub-epithelial region of the mucosa, ${ }^{37}$ and electron microscopy showed prominent degranulating mast cells in parasitized children that was associated with high rates of spontaneous histamine release from tissue biopsies ${ }^{37}$ indicating that immediate hypersensitivity reactions were ineffective in expelling T. trichiura adults. ${ }^{37}$ Children with TDS have increased numbers of mucosal cells expressing TNF$\alpha$ and increased levels of TNF- $\alpha$ in the peripheral circulation and TNF- $\alpha$ production by isolated mucosal cells. ${ }^{39}$

(3) Hookworm-Adult worms live with their anterior ends dug deep within the mucosa of the distal duodenum and proximal jejunum. Data on primary infections with hookworm in humans have been obtained from experimental human infections with $N$. americanus and have shown little attrition of hookworm larvae during systemic migration, ${ }^{40,41}$ and no apparent pulmonary reactions to migrant larvae. ${ }^{40-43}$ However, all experimentally infected individuals developed eosinophilic enteritis, accompanied by blood eosinophilia ${ }^{40-44}$ and the presence of Charcot-Leyden crystals in feces. ${ }^{21}$ The reactions were restricted to immature worms, and during repeat infections, the mucosal histology was normal at sites adjacent to mature worms. ${ }^{41}$ Chronic hookworm infections are generally associated with a normal-appearing mucosa-a study of 28 infected patients failed to find total villous atrophy in any in the upper small bowel, and only 4 had partial villous atrophy, crypt hyperplasia, and increased inflammatory infiltrate in the lamina propria, ${ }^{45}$ consistent with previous studies. ${ }^{46,47}$

(4) S. stercoralis-Eggs produced by females buried in jejunal mucosa rapidly transform into rhabditiform larvae that can become flariform within $24 \mathrm{~h}$ and may penetrate the colonic mucosa causing autoinfection. Jejunal histology tends to be normal during chronic infections. ${ }^{48,49}$

In summary, during first infections with geohelminth parasites, A. lumbricoides but not hookworm infections stimulate a vigorous inflammatory response in the lungs to migrating larvae. Establishment of infections in the intestinal tract may be associated with eosinophilic enteritis during infections with juvenile hookworms. Chronic intestinal infections are associated with minimal inflammatory response in the mucosa and mild histologic alterations (e.g., partial villus atrophy), reflecting active immune regulation by host and or parasite. A study of duodenal biopsy samples from individuals infected with geohelminths and noninfected controls showed expression of IL- 5 in both groups but few other changes. ${ }^{50}$

Clearly, the histological picture and immunological effects in the mucosa will vary between individuals and may depend on an individual's history of infection (e.g., maternal infection, age of first infection, and intensity of transmission), present parasite burden, and host genetics. Thus, a complex array of factors determine immunological outcomes in individuals and may explain the difficulties in the interpretation of ex vivo immunological data in humans compared with animal models that are often single genetic strains receiving well-defined infectious doses at single or, occasionally, multiple time points. Geohelminth infections in humans may have profound effects on human immunity that may be programmed in early life, ${ }^{51,52}$ and may be only partially reversible by long-term anthelmintic treatment. ${ }^{53}$

Chronic infections in some individuals may be associated with severe inflammation (e.g., TDS) but most children are likely to be asymptomatic. Chronic infections downregulate inflammatory responses in the intestinal mucosa to avoid the long-term consequences of an inflamed intestinal mucosa on host nutrition. During initial infections, benefit to the host may be obtained by mounting inflammatory responses to expel parasites.

The minimal effects of chronic infections on mucosal inflammation and histology may indicate profound immune regulation. The mechanisms by which chronic human geohelminth infections modulate mucosal immunity in the presence of infection are poorly understood but are likely to include those described for animal models of helminth infection including the suppression of dendritic cell responses to TLR ligands ${ }^{54,55}$ and the capacity to produce IL-12, ${ }^{54,56}$ resulting in a Th2-predominant environment that promotes the development of alternatively activated macrophages ${ }^{57}$ and immune cells that produce 
the anti-inflammatory cytokine, IL-10. Populations of regulatory T cells (Tregs) are important mediators of immune regulation in animal models including the so-called natural CD4 + Tregs that are CD25 + and FoxP $3+.{ }^{58}$

Putative mechanisms that have been identified as important in the modulation of immunity ex vivo in PBLs collected from individuals infected with tissue helminths (e.g., filarial and schistosome infections) may be relevant to the modulation of mucosal inflammatory responses during geohelminth infections. During chronic tissue helminth infections, immune cells have been shown to produce high levels of IL-10 in vitro, ${ }^{59-63}$ and neutralization of IL-10 and or transforming growth factor- $\beta$ (TGF- $\beta$ ) partially reversed this hyporesponsiveness. ${ }^{59-62}$ The majority of IL-10-expressing cells in human filarial infections were CD4 + CD25 - T cells, although many other immune cell types expressed IL-10 also. ${ }^{64}$ CTLA-4, which provides an inhibitory signal for T-cell co-stimulation, was more frequently present on $\mathrm{T}$ cells of patients with chronic filarial infections compared with uninfected controls, and neutralization of CTLA-4 enhanced Th2 cytokine production. ${ }^{65}$ Exposure of PBLs from infected patients to live larvae or microfilariae of Brugia malayi caused a profound suppression of cytokine responses that was associated with reduced transcription of T-bet and GATA-3, increased expression of FoxP3 and other regulatory markers (e.g., CTLA-4, TGF- $\beta$, PD-1, and ICOS), enhanced induction of anergy-associated factors (e.g., cbl, Itch, and Nedd4), and was reversed by neutralization of CTLA- 4 and TGF- $\beta .^{66}$

There is limited evidence for increased IL-10 production during human A. lumbricoides infection ${ }^{14,67}$ or increased frequencies of parasite antigen-induced T cells expressing IL$10,{ }^{67}$ and no evidence for alteration of cytokine responses by PBLs after neutralization of IL-10 or TGF- $\beta .{ }^{14}$ A small study of children infected in Cameroon provided some evidence for increased production of IL- 10 and TGF- $\beta 1$ by unstimulated PBLs that were associated positively with infection intensities with A. lumbricoides and T. trichiura and inversely with immune reactivity. ${ }^{68}$ PBLs from humans infected with hookworm show different responses to antigens from different parasite life-cycle stages compared to egg-negative individuals with impaired proliferation to larval L3 antigen and reduced cytokine responses to adult worm excretory/secretory $(\mathrm{E} / \mathrm{S})$ antigens. ${ }^{69}$ Furthermore, dendritic cells generated in vitro from infected individuals and cocultured with adult $\mathrm{E} / \mathrm{S}$ antigens had lower expression of CD86, CD1a, HLA-ABC, and HLA-DR, and a reduced capacity to promote cell proliferation. ${ }^{70}$ No consistent effects, however, were observed of hookworm infection on IL-10 secretion. ${ }^{69,71}$

There are few reported studies of the effects of geohelminth infections on mucosal immunity in humans. There is a need for studies of mucosal immune responses during infection that compare well-defined groups of geohelminth-infected patients with appropriate controls. Prospective studies could examine histological and immunological changes in mucosal immunity before and after experimental infections (e.g., therapeutic hookworm infections) or before and after treatment in chronically infected individuals (i.e., reversibility).
A common finding among apparently healthy individuals living in the tropics is tropical or environmental enteropathy characterized by small intestinal changes of partial villous atrophy, crypt hypertrophy, and an increased inflammatory infiltrate..$^{72-75}$ Biopsy samples of the large intestine show a nonspecific inflammatory infiltrate in the colon. ${ }^{76}$ Chronic geohelminth infections may contribute to these findings but so may other factors such as undernutrition, other intestinal parasite infections, bacterial pathogens, and extensive bacterial colonization of the upper small intestine. ${ }^{77}$

\section{Potential effects of geohelminths on nonparasite immune responses}

There has been considerable interest in the potential effects of geohelminths in modulating inflammatory diseases of the mucosa, and these parasites may have important effects on the immune response to oral vaccines and susceptibility to other infectious diseases.

Asthma. The prevalence of asthma has increased over recent decades and it is now the commonest chronic disease of childhood in $\mathrm{HICs}^{78}$ and is estimated to affect at least $20 \%$ of school-age children in the United Kingdom. ${ }^{79}$ The prevalence appears to be increasingly in LMICs, particularly in urban centers of Latin America where the prevalence has reached alarming rates. ${ }^{79,80}$ These temporal trends in asthma prevalence are likely to have been caused by changes in environmental exposures such as lifestyle and hygiene-related factors. ${ }^{80-82}$

There has been considerable interest in the potential protective effects of helminth parasites against allergic inflammation. Experimental animal models have provided clear and compelling data to support the hypothesis that intestinal helminth infections can modulate inflammation in the airways. ${ }^{83,84}$ The intestinal helminth, Heligmosoides polygyrus, that does not migrate through the lungs, has been shown to suppress allergen-induced airway eosinophilia ${ }^{85,86}$ and bronchial hyperreactivity ${ }^{85}$ induced by sensitization with ovalbumin (OVA $)^{85,86}$ or Dermatophagoides pteronyssinus allergen $\mathrm{p} 1$ (Der $\mathrm{p} 1) .{ }^{86}$ Suppression was transferable to uninfected animals by splenocytes ${ }^{85}$ or mesenteric lymph node cells ${ }^{86}$ and was associated particularly with $\mathrm{CD} 4+\mathrm{CD} 25+\mathrm{T}$ cells. It is unclear whether the mechanism of suppression is IL-10-depend$\mathrm{ent}^{85-87}$ or whether other cell populations can transfer suppression. Nippostrongylus brasiliensis, an intestinal helminth parasite used as a model for human hookworm infection, that migrates transiently through the lungs can induce macrophages to acquire an alternatively activated phenotype during primary infections, ${ }^{88}$ and infections are associated with a protracted suppression of airway hyperreactivity and inflammation to D. pteronyssinus. ${ }^{89}$

Findings from human studies have been less compelling. There is some evidence that geohelminth infections may, under different circumstances, be protective or risk factors for asthma. ${ }^{90}$ However, helminth infections in human populations are just one of many interacting environmental and genetic factors that may determine asthma development. Further complexity is provided by age- and intensity-dependent exposure effects and multiple asthma phenotypes (e.g., atopic vs. non-atopic) $)^{91,92}$ that appear 
to be associated with different patterns of risk factors ${ }^{93,94}$ and genetic predisposition. ${ }^{95}$

A recent meta-analysis of observational epidemiological studies showed an inverse association between asthma and hookworm infection from three studies conducted in Ethiopia, ${ }^{96-98}$ but a positive association between $A$. lumbricoides infections and asthma risk in other regions. ${ }^{99}$ Several more recent studies have reported positive associations between the presence of antiAscaris $\operatorname{IgE}^{100-102}$ or active A. lumbricoides infection $94,103,104$ and asthma symptoms or bronchial hyperresponsiveness (BHR) in low-prevalence populations. A. lumbricoides infections could enhance airways reactivity by the inflammatory effects of migratory larvae in the airways or by Th2-adjuvant effects of parasite antigens ${ }^{105}$ on immune responses to aeroallergens. The observation of an inverse association between hookworm infection and asthma has motivated therapeutic studies evaluating the role of hookworm infection in the treatment of asthma. ${ }^{106}$

Chronic helminth infections are associated with potent suppression of allergic inflammatory responses directed against the parasite, ${ }^{90}$ but it is less clear whether such infections can modulate allergic inflammation directed against nonparasite allergens such as aeroallergens that have been most commonly associated with allergic inflammatory processes.

Allergic sensitization or atopy in humans can be determined by measurement of allergen-specific IgE in serum or skin test reactivity to allergen extracts. Parasite-antigen-induced IL-10 has been shown to be inversely associated with allergen skin test reactivity during Schistosoma haematobium infections. ${ }^{107}$ The same study showed also that increasing levels of IL-10 appeared to reduce the risk of a positive skin test to D. pteron$y$ ssinus associated with the presence of a given level of specific IgE. ${ }^{107}$ However, a study of immunologic parameters associated with allergen skin test reactivity among geohelminth-infected children was unable to show any association with Ascaris antigen-induced production of IL-10 by PBLs or IL-10 expression by $\mathrm{T}$-cell populations, or any effect of these immune variables on the association between specific IgE and skin test reactivity to aeroallergens. ${ }^{67}$ There is some evidence that helminthinfected asthmatics have a more attenuated form of disease than do noninfected asthmatics. ${ }^{108}$ Peripheral blood mononuclear cells (PBMCs) from infected asthmatics produce higher levels of IL-10 to Der p 1 than noninfected controls. ${ }^{109}$

The effects of geohelminth infections on anti-parasite immune responses may be partially reversed by long-term anthelmintic treatment. ${ }^{53,110}$ If geohelminths were to be actively suppressing allergic responses, anthelmintic treatment might be expected to reverse this effect. Two small intervention studies have provided evidence that anthelmintic treatment of children may increase allergen skin test reactivity, ${ }^{111,112}$ but a much larger randomized controlled trial was unable to replicate these findings and showed no treatment effect on asthma symptoms. ${ }^{113}$ A study investigating the effects of anthelmintic treatment on asthma symptoms in population with a low prevalence of infection observed an improvement in symptoms after treatment. ${ }^{114}$ The discrepant findings between studies might be explained by differences in the type of and prevalence of parasites between different populations. ${ }^{51}$
Early infant or even maternal geohelminth infections may have profound long-term effects on infant immunity ${ }^{52}$ that may include suppression of allergic responses to nonparasite allergens, ${ }^{115}$ and these effects may not be reversible by anthelmintic treatment at school age. ${ }^{51,113}$ There is clearly a need for prospective studies to evaluate the effects of early geohelminth infections on the early development of mucosal immune responses and the development of asthma and other atopic diseases. Such studies should start from birth with follow-up to school age when allergic disease outcomes can be more reliably determined.

An important observation from epidemiological studies has been the apparent disassociation between allergic sensitization and the risk of asthma symptoms, ${ }^{116}$ particularly in developing regions of the world such as Latin America. ${ }^{80,94,117,118}$ Phase II of the International Study of Asthma and Allergies in Childhood (ISAAC) showed stronger associations between atopy and asthma in HICs compared with LMICs: ${ }^{118}$ the proportion of asthma attributable to atopy in Brazilian and Ecuadorian centers was just $11 \%$. The observations of weak associations between asthma and atopy and recent genetic studies that point to an underlying epithelial abnormality ${ }^{119}$ make it unlikely that allergic sensitization has a primary role in the development of asthma. If this is the case, then most current animal models of asthma that are based on the induction of BHR by allergen sensitization may be flawed. Such a paradigm shift in asthma research has important implication for the study of the effects of helminths on asthma. Future human studies should focus on subgroups of patients (i.e., those with atopic asthma) to investigate the effects of geohelminths on mucosal immunity to aeroallergens in the lungs. Therapeutic studies of the effects of hookworm infection on asthma will provide opportunities to study such effects under well-controlled conditions although ethical issues may preclude the study of chronic and high-intensity infections.

Inflammatory bowel disease. Inflammatory bowel diseases (IBD) including Crohn's diseases and ulcerative colitis are associated with impairments in epithelial dysfunction and dysregulated immune responses to normal commensal enteric bacteria. ${ }^{120}$ The development of IBD is associated with complex gene-environment interactions. ${ }^{121} \mathrm{IBD}$ has increased in prevalence over recent decades in HICs, ${ }^{122-125}$ and it has been suggested that these trends may be explained by improved hygiene and the disappearance of geohelminth infections. ${ }^{126}$ If such a hypothesis was true then we might expect to see an increase in the prevalence of IBD in many LMICs where helminth parasites are becoming less prevalent, and there is some evidence that this might be the case. ${ }^{127,128}$

Several models have shown that infections with intestinal helminths ${ }^{129-131}$ and other helminth parasites ${ }^{126,132}$ can ameliorate chemical-induced colitis. Furthermore, the Th2 response induced by the intestinal worm, $H$. polygyrus, has also been shown to attenuate experimental gastritis caused by Helicobacter pylori infection. ${ }^{133}$ The mechanisms by which helminths may protect against chemical-induced inflammation of the intestine may include the induction of a Th2-dominated cytokine milieu in the intestinal mucosa, ${ }^{134,135}$ downregulation of Th1 ${ }^{131,136,137}$ 
and Th17 mucosal responses, ${ }^{138}$ upregulation of IL-10 and TGF$\beta$ by mucosal immune cells, ${ }^{128,135}$ the induction of alternatively activated macrophages in the intestinal mucosa, ${ }^{139}$ and by regulatory effects on mucosal innate immune responses. ${ }^{140-142}$

The regulatory effects of intestinal helminths may not be restricted to the sites of infestation but may extend to distal mucosal sites. ${ }^{135}$ Promising results have been obtained by the treatment of mice with helminth parasite products such as schistosome eggs, ${ }^{143}$ schistosome adult worm antigen, ${ }^{144}$ and hookworm excretory/secretory proteins. ${ }^{144}$ Future studies are likely to focus on protection mediated by parasite components. However, not all experimental animal models have shown a beneficial effect of intestinal helminths on intestinal inflammation-a model of Th2-induced chemical colitis showed that concurrent intestinal helminth infections may exacerbate disease. ${ }^{145}$

Several research groups have evaluated the usefulness of therapeutic infections with intestinal helminths in IBD patients. The first parasite used was pig whipworm, Trichuris suis, that does not cause disease in humans ${ }^{146-148}$ although it may be tissue invasive. ${ }^{149,150}$ This treatment has been used extensively in the United States and Europe ${ }^{151}$ although there is still very limited published literature documenting the effects of this treatment in humans (Table 2) and a single randomized controlled trial of 54 patients with ulcerative colitis. ${ }^{147}$ All studies have reported temporary improvements in symptoms. ${ }^{146-148}$ None have reported the impact of these therapeutic infections on immunological or inflammatory parameters in the mucosa. There is a need for detailed prospective evaluations of mucosal immunity in the intestine during therapeutic infections with helminth parasites.

T. suis remains an investigational treatment with unproven efficacy-treatment with T. suis ova may be useful in specific subgroups of patients with IBD and large multicenter randomized trials that are in progress should define the therapeutic role if any for this treatment. ${ }^{128}$ The lack of symptoms associated with T. suis infection would suggest that any modulatory effects on mucosal inflammation is mediated directly by the parasite and may last only for the duration of this self-limiting infection. It is unlikely that the host would respond to an apparently innocuous infection by the induction of potent regulatory mechanisms. More recently, the therapeutic effects of N. americanus infections for the treatment of Crohn's disease have been evaluated in a small "proof of concept" study and provided some evidence for reductions in disease activity scores in a group of 9 patients. $^{21}$

\section{Co-infections}

Infectious inflammation of the large intestine. Infectious colitis is extremely common among children under 5 years of age in the rural tropics and is caused by pathogens such as enterohemorrhagic and enteroinvasive Escherichia coli, Shigella spp, and Campylobacter jejuni. ${ }^{152}$ Mucohemorrhagic diarrhea may occur during T. trichiura co-infections with amoebiasis and shigellosis, ${ }^{153}$ but a hospital-based study in rural Ecuador was unable to show such an association. ${ }^{154}$ Recent observations in experimental murine models and pigs infected with $T$. suis suggest that concurrent geohelminth infections may suppress mucosal immunity sufficiently to cause severe bacterial colitis.

Citrobacter rodentium is a Gram-negative bacterial pathogen used as a model for enteropathogenic $E$. coli infections. Mice co-infected with $H$. polygyrus and C. rodentium developed severe colitis associated with significant morbidity and mortality. ${ }^{134}$ The increased pathology observed in co-infected mice was STAT6-dependent, associated with enhanced mucosal Th2 responses, a downregulation of protective interferon- $\gamma$ (IFN$\gamma$ ) responses, and marked upregulation of pro-inflammatory TNF- $\alpha$ by the intestinal mucosa. ${ }^{134}$ Subsequent studies using the same model showed that the colitis was associated with IL10-producing dendritic cells ${ }^{140}$ and that alternatively activated macrophages in the lamina propria were impaired in bacteria killing. ${ }^{139}$

Mucohemorrhagic enteritis, a severe necrotic colitis of pigs, has been described after inoculation with T. suis and may be caused by overgrowth of resident bacteria. ${ }^{155}$ Furthermore, pigs co-infected with C. jejuni and T. suis develop a more severe colitis than those infected with either pathogen alone, ${ }^{156}$ but may be mediated partly by toxic effects of Trichuris excretory/secretory products on intestinal epithelial cells. ${ }^{157}$

Tuberculosis, HIV, and malaria. There is an extensive literature of the potential effects of geohelminth infections on susceptibility to infections with Mycobacterium tuberculosis, ${ }^{158}$ human immunodeficiency virus, ${ }^{159,160}$ and malaria. ${ }^{161}$ Although there may be measurable immunological effects arising from these interactions, there is still no compelling data to support significant clinical effects of geohelminths on these infections. However, few studies have measured such effects and there is a need for large, adequately powered and designed studies in endemic populations to investigate these interactions.

Leishmaniasis. Patients with cutaneous leishmaniasis and infected with geohelminths have delayed healing after antimony treatment and increased IL-5 compared with those without geohelminths. ${ }^{162}$ There is some experimental evidence to support an interaction between helminths and Leishmania infection-mice infected with Taenia crassiceps and subsequently co-infected with Leishmania major and L. mexicana had increased Th2 and decreased Th1 cytokine responses associated with enhancement of disease. ${ }^{163}$ Impaired immunity caused by geohelminths could contribute to the risk of mucocutaneous disease associated with previous infections with Leishmania braziliensis.

Helminth interactions. Humans living in endemic areas for geohelminth parasites are commonly infected with multiple geohelminths, although it is not clear whether the specific patterns of co-infections are a consequence of shared risk factors or immune or other interactions. ${ }^{164}$ Murine experimental models have shown that when mice normally susceptible to $T$. muris infection are co-infected with Schistosomiasis mansoni, they develop the ability to expel T. muris by a Th2-cytokine-associated mechanism. ${ }^{165}$ Furthermore, mice chronically infected with $T$. muris and subsequently co-infected with $S$. mansoni developed higher worm and hepatic egg burdens than those without T. muris infection. ${ }^{166}$ T. muris infection was associated with reduced trapping of $S$. mansoni larvae in the lungs 
Table 2 Summary of published human studies investigating effects of intestinal helminth parasites on mucosal immunity and disease

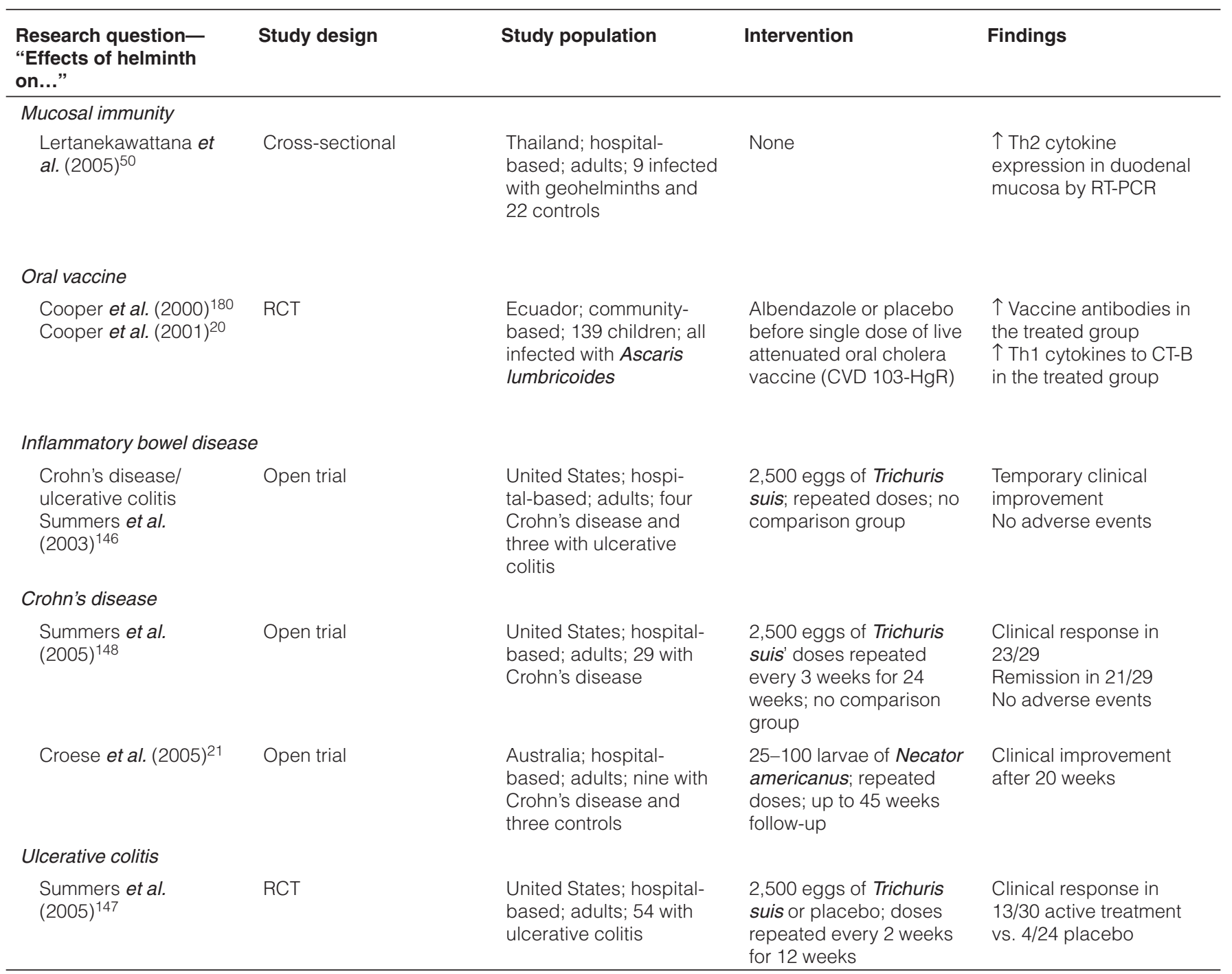

CT-B, cholera toxin B-subunit; RCT, randomized controlled trial; RT-PCR, reverse transcriptase PCR; $\uparrow$, increase in.

indicating that chronic T. muris infections may have potent immune regulatory effects that extend beyond the intestinal tract. ${ }^{166}$ An H. polygurus and S. mansoni co-infection model showed that the intestinal helminth infection attenuated hepatic pathology caused by S. mansoni eggs and reduced pro-inflammatory cytokine production. ${ }^{167}$

Mucosal vaccines. Mucosal vaccines stimulate immune cells in mucosal-inductive sites and induce both mucosal and systemic immunity. Mucosal vaccines can be delivered to mucosal surfaces through the rectal, vaginal, conjuntival, oral, and nasal routes. Currently there are few mucosal vaccines being used extensively in human populations - trivalent oral poliovirus $(\mathrm{OPV})$ and oral rotavirus vaccines are the only examples-but there are a large number under development and it is likely that new mucosal vaccines may become available for vaccination programs over the next few years.

Live attenuated oral vaccines are less immunogenic in poor populations ${ }^{168-175}$ requiring an increase in the dose or number of doses administered to achieve adequate vaccine immunity. ${ }^{169,176}$ Both OPV and rotavirus vaccines are less immunogenic in poor compared with wealthier populations. ${ }^{177-179}$

Geohelminth infections may have deleterious effects on immunity to oral vaccines. Children infected with geohelminths had reduced vibriocidal antibody levels ${ }^{180}$ and Th1 cytokine responses to cholera toxin $\mathrm{B}$-subunit ${ }^{20}$ after vaccination with live attenuated oral cholera vaccine (CVD 103-HgR), and these deficits were reversed partially by anthelmintic treatment before vaccination. ${ }^{20,180}$ Similarly, $H$. polygyrus infection of mice interfered with Th1 cytokine and antibody responses to OVA after vaccination with an OVA-expressing oral Salmonella vaccine. ${ }^{181}$ However, geohelminth infections alone are unlikely to explain impaired immunity to oral vaccines. A recent study investigating the impact of $A$. lumbricoides infection on responses to oral BCG Moreau failed to show post-vaccination increases in the frequencies of tuberculin-stimulated PBMCs expressing IFN- $\gamma$ among children with either active infections or those who had 
received either short or long courses of anthelmintics before vaccination (Vaca, M., Moncayo, A.L., Cosgrove, C., Chico, M.E., Lewis, D.J. \& Cooper, P.J., unpublished data). The same vaccine showed strong boosting of post-vaccination IFN- $\gamma$ responses in wealthier populations. ${ }^{25,26}$ These data indicate the presence of a mucosal barrier to oral vaccination among children living in the rural tropics that is independent of geohelminth infections. Other factors that may interfere with the interaction between vaccine and mucosa include tropical enteropathy, ${ }^{9-74}$ small intestinal bacterial overgrowth, ${ }^{73}$ and intestinal microbiota.

Geohelminth infections, which are acquired after 9 months of age in infants, are unlikely to interfere with immunity to vaccines given before this time but may have effects on booster vaccines given later. Maternal geohelminth infections could affect infant immunity, ${ }^{52,182,183}$ cause long-term perturbations in mucosal immune responses, and interfere with early infant responses to mucosal vaccines (Cooper, P.J., Yerovi, G., Guadalupe, I., Quichimbo, M., Chico, M.E., Iturizza, M. et al., unpublished data), although the mechanisms by which they might have this effect are unknown.

\section{CONCLUSION}

Geohelminth infections live in intimate contact with the intestinal epithelium and may stimulate strong inflammatory responses locally in the mucosa during primary infections and potent regulatory responses during chronic infections that may extend to distal mucosal sites in the intestine and other organs such as the lung. Experimental intestinal helminth infections in animals are associated with inflammatory responses during primary infections that serve to expel or kill luminal parasites. In contrast, chronic infections are associated with immune regulation by multiple mechanisms that serve to dampen host inflammatory responses and to prevent the long-term pathological and nutritional consequences of chronic inflammation of the intestinal mucosa. There are surprisingly few studies of human geohelminth infections documenting the mucosal response to infection, but the few data available partly support the observations from animal models. The histological changes observed during chronic geohelminth infections are surprisingly mild in most cases and may reflect a highly adapted host-parasite interaction.

It has been suggested that human geohelminth infections may modulate asthma and inflammatory bowel disease, although data to support important clinical effects in human populations are limited. Concurrent geohelminth infections may affect mucosal immunity to oral vaccines but other factors are also likely to be important (e.g., intestinal microflora, and tropical enteropathy) that together may contribute to form a barrier to mucosal immunization. The efficacy of new mucosal vaccines in infants from poor populations in LMICs will require detailed evaluation in geohelminth-endemic settings before widespread distribution.

Geohelminth parasites are likely to release molecules that modulate mucosal inflammation. The identification of such molecules has potential for the development of new therapies for inflammatory diseases of the mucosa. Therapeutic infections or inoculations with parasite extracts may induce multiple regulatory pathways, whereas therapy with single molecules such as the filarial nematode immunomodulatory molecule ES-62 ${ }^{184}$ may target one or few inflammatory pathways. Single-molecule therapy is likely to be most useful for subgroups of patients in whom specific inflammatory mechanisms mediate disease, and such individuals may be identifiable by specific genetic characteristics. Treatments that are effective in larger groups of patients will almost inevitably require cocktails of molecules that target multiple inflammatory pathways and carry the risk of adverse reactions caused by immunosuppression.

There is a need for further research on the effects of geohelminths on mucosal immune responses in endemic settings in LMICs. Such research is likely to enhance our understanding of the regulation of inflammation and the causes of the growing epidemic of inflammatory diseases.

\section{ACKNOWLEDGMENTS}

PJC is supported by Wellcome Trust (Grant no. 074679/Z/04/Z).

\section{DISCLOSURE}

The authors declare no conflict of interest.

\section{C) 2009 Society for Mucosal Immunology}

\section{REFERENCES}

1. Savioli, L., Engels, D. \& Endo, H. Extending the benefits of deworming for development. Lancet 365, 1520-1521 (2005).

2. Cooper, P.J., Ayre, G., Martin, C., Sarinho, E. \& Cruz, A. Geohelminth infections: a review of the role of lgE and assessment of potential risks of anti-lgE treatment. Allergy 63, 409-417 (2008).

3. Stoltzfus, R.J. et al. Epidemiology of iron deficiency anemia in Zanzibari schoolchildren: the importance of hookworms. Am. J. Clin. Nutr. 65, 153-159 (1997).

4. Beasley, N.M. et al. The impact of population level deworming on the haemoglobin levels of schoolchildren in Tanga, Tanzania. Trop. Med. Int. Health 4, 744-750 (1999).

5. Stephenson, L.S., Latham, M.C., Adams, E.J., Kinoti, S.N. \& Pertet, A. Weight gain of Kenyan school children infected with hookworm, Trichuris trichiura and Ascaris lumbricoides is improved following once- or twiceyearly treatment with albendazole. J. Nutr. 123, 656-665 (1993).

6. Stephenson, L.S., Latham, M.C., Adams, E.J., Kinoti, S.N. \& Pertet, A. Physical fitness, growth and appetite of Kenyan school boys with hookworm, Trichuris trichiura and Ascaris lumbricoides infections are improved four months after a single dose of albendazole. J. Nutr. 123, 1036-1046 (1993).

7. Taylor-Robinson, D.C., Jones, A.P. \& Garner, P. Deworming drugs for treating soil-transmitted intestinal worms in children: effects on growth and school performance. Cochrane Database Syst. Rev. 4, CD000371 (2007).

8. Dickson, R., Awasthi, S., Williamson, P., Demellweek, C. \& Garner, P. Effects of treatment for intestinal helminth infection on growth and cognitive performance in children: systematic review of randomised trials. BMJ 320, 1697-1701 (2000).

9. Alderman, H., Konde-Lule, J., Sebuliba, I., Bundy, D. \& Hall, A. Effect on weight gain of routinely giving albendazole to preschool children during child health days in Uganda: cluster randomised controlled trial. BMJ 333, 122 (2006).

10. Awasthi, S. et al. Effects of deworming on malnourished preschool children in India: an open-labelled, cluster-randomized trial. PLoS Negl. Trop. Dis. 2, e223 (2008).

11. Artis, D. \& Grencis, R.K. The intestinal epithelium: sensors to effectors in nematode infection. Mucosal. Immunol. 1, 252-264 (2008).

12. Dawson, H.D. et al. Localized multigene expression patterns support an evolving Th1/Th2-like paradigm in response to infections with Toxoplasma gondii and Ascaris suum. Infect. Immun. 73, 1116-1128 (2005).

13. Mahanty, S. et al. IL-4- and IL-5-secreting lymphocyte populations are preferentially stimulated by parasite-derived antigens in human tissue invasive nematode infections. J. Immunol. 151, 3704-3711 (1993). 
14. Cooper, P.J. et al. Human infection with Ascaris lumbricoides is associated with a polarized cytokine phenotype. J. Infect. Dis. 182, 1207-1213 (2000)

15. Jackson, J.A. et al. Thelper cell type 2 responsiveness predicts future susceptibility to gastrointestinal nematodes in humans. J. Infect. Dis. 190, 1804-1811 (2004).

16. Anthony, R.M., Rutitzky, L.I., Urban, J.F. Jr, Stadecker, M.J. \& Gause, W.C. Protective immune mechanisms in helminth infection. Nat. Rev. Immunol. 7, 75-987 (2007).

17. Turner, J.D. et al. Th2 cytokines are associated with reduced worm burdens in a human intestinal helminth infection. J. Infect. Dis. 188, 1768-1775 (2002).

18. Quinnell, R.J. et al. Immune responses to human necatoriasis: association between interleukin-5 responses and resistance to reinfection. J. Infect. Dis. 190, 430-438 (2004).

19. Finkelman, F.D. et al. Cytokine regulation of host defense against parasitic gastrointestinal nematodes: lessons from studies with rodent models. Annu. Rev. Immunol. 15, 505-533 (1997).

20. Cooper, P.J. et al. Human infection with Ascaris lumbricoides is associated with suppression of the $\mathrm{LL}-2$ response to recombinant cholera toxin B-subunit following vaccination with the live oral cholera vaccine CVD 103 HgR. Infect. Immun. 69, 1574-1580 (2001).

21. Croese, J. et al. A proof of concept study establishing Necator americanus in Crohn's patients and reservoir donors. Gut. 55, 136-137 (2006).

22. Needham, C.S. et al. Potential for diagnosis of intestinal nematode infections through antibody detection in saliva. Trans. R. Soc. Trop. Med. Hyg. 90, 526-530 (1996)

23. Lewis, D.J., Novotny, P., Dougan, G. \& Griffin, G.E. The early cellular and humoral immune response to primary and booster oral immunization with cholera toxin B subunit. Eur. J. Immunol. 21, 2087-2094 (1991).

24. Castello-Branco, L.R., Griffin, G.E., Poulton, T.A., Dougan, G. \& Lewis, D.J. Characterization of the circulating T-cell response after oral immunization of human volunteers with cholera toxin B subunit. Vaccine 12, 65-72 (1994).

25. Monteiro-Maia, R., Ortigão-de-Sampaio, M.B., Pinho, R.T. \& CastelloBranco, L.R. Modulation of humoral immune response to oral BCG vaccination by Mycobacterium bovis BCG Moreau Rio de Janeiro (RDJ) in healthy adults. J. Immune Based Ther. Vaccines 4, 4 (2006).

26. Cosgrove, C.A. et al. Boosting of cellular immunity against Mycobacterium tuberculosis and modulation of skin cytokine responses in healthy human volunteers by Mycobacterium bovis BCG subtrsain Moreau Rio de Janeiro oral vaccine. Infect. Immun. 74, 2449-2452 (2006).

27. Wasserman, S.S. et al. Kinetics of the vibriocidal antibody response to live oral cholera vaccines. Vaccine 12, 1000-1003 (1994).

28. Garside, P., Kennedy, M.W., Wakelin, D. \& Lawrence, C.E. Immunopathology of intestinal helminth infection. Parasite Immunol. 22, 605-612 (2000).

29. Shea-Donohue, T. \& Urban, J.F. Jr. Gastrointestinal parasite and host interactions. Curr. Opin. Gastroenterol. 20, 3-9 (2004).

30. Arean, V.M. \& Crandall, C.A. Ascariasis. In Pathology of Protozoal and Helminthic Diseases (Marcial-Rojas, R.A.) 769-807 (Williams \& Wilkins, New York, 1971)

31. Gelpi, A.P. \& Mustafa, A. Ascaris pneumonia. Am. J. Med. 44, 377-389 (1968).

32. Spillmann, R.K. Pulmonary ascariasis in tropical communities. Am. J. Trop. Med. Hyg. 24, 791-800 (1975).

33. Miquel, N., Roepstorff, A., Bailey, M. \& Eriksen, L. Host immune reactions and worm kinetics during the expulsion of Ascaris suum in pigs. Parasite Immunol. 27, 79-88 (2005).

34. Marbella, C.O. \& Gaafar, S.M. Production and distribution of immunoglobulin-bearing cells in the intestine of young pigs infected with Ascaris suum. Vet. Parasitol. 34, 63-70 (1989).

35. MacDonald, T.T. Mucosal immunity in human chronic helminthic disease and gut inflammation. In Allergy and Immunity to Helminths: Common Mechanisms or Divergent Pathways (Moqbel, R.) 137-153 (Taylor \& Francis Ltd, London, 1992).

36. Bundy, D.A. \& Cooper, E.S. Trichuris and trichuriasis in humans. Adv. Parasitol. 28, 107-173 (1989).

37. Cooper, E.S. et al. Immediate hypersensitivity in colon of children with chronic Trichuris trichiura dysentery. Lancet 338, 1104-1107 (1991).
38. MacDonald, T.T. et al. Histopathology and immunohistochemistry of the caecum in children with the Trichuris dysentery syndrome. J. Clin Pathol. 44, 194-199 (1991).

39. MacDonald, T.T. et al. Immunoepidemiology of intestinal helminthic infections. 3. Mucosal macrophages and cytokine production in the colon of children with Trichuris trichiura dysentery. Trans. R. Soc. Trop. Med. Hyg. 88, 265-268 (1994).

40. Croese, J., Wood, M.J., Melrose, W. \& Speare, R. Allergy controls the population density of Necator americanus in the small intestine. Gastroenterology 131, 402-409 (2006).

41. Croese, J. \& Speare, R. Intestinal allergy expels hookworms: seeing is believing. Trends Parasitol. 22, 547-550 (2006)

42. Maxwell, C. et al. The clinical and immunologic responses of normal human volunteers to low dose hookworm (Necator americanus) infection. Am. J. Trop. Med. Hyg. 37, 126-134 (1987).

43. Wright, V. \& Bickle, Q. Immune responses following experimental human hookworm infection. Clin. Exp. Immunol. 142, 398-403 (2005).

44. Geiger, S.M., Fujiwara, R.T., Santiago, H., Correa-Oliveira, R. \& Bethony, J.M. Early stage-specific immune responses in primary experimental hookworm infection. Microbes Infect. 10, 1524-1535 (2008).

45. Burman, N.N., Sehgal, A.K., Chakravarti, R.N., Sodhi, J.S. \& Chhuttani, P.N. Morphological and absorption studies of small intestine in hookworm infestation (ankylostomiasis). Indian J. Med. Res. 58, 317325 (1970).

46. Chaudhuri, R.N. \& Saha, J.K Jejunal mucosa in hookworm disease. Am. J. Trop. Med. Hyg. 13, 410-411 (1964).

47. Tandon, B.N., Das, B.C., Saraya, A.K. \& Deo, M.G. Functional and structural studies of small bowel in ankylostomiasis. BMJ 1, 714-716 (1996).

48. O'Brien, W. Intestinal malabsorption in acute infection with Strongyloides stercoralis. Trans. R. Soc. Trop. Med. Hyg. 69, 69-77 (1975).

49. Garcia, F.T. et al. Intestinal function and morphology in strongyloidiasis. Am. J. Trop. Med. Hyg. 26, 859-865 (1977).

50. Lertanekawattana, S., Wichatrong, T., Chaisari, K., Uchikawa, R. \& Arizono, N. Immunological characteristics of patients infected with common intestinal helminths: results of a study based on reversetranscriptase PCR. Ann. Trop. Med. Parasitol. 99, 71-80 (2005).

51. Cooper, P.J., Barreto, M. \& Rodrigues, L.C. Human allergy and intestinal helminth infections: a review of the literature and discussion of a conceptual model to investigate the possible causal association. Br. Med. Bull. 79-80, 203-318 (2006).

52. Cooper, P.J. The potential impact of early exposures to geohelminth infections on the development of atopy. Clin. Rev. Allergy Immunol. 26, 5-14 (2004).

53. Cooper, P.J. et al. Repeated albendazole treatments enhance Th2 responses to Ascaris lumbricoides but not aeroallergens in children from rural communities in the Tropics. J. Infect. Dis. 198, 1237-1242 (2008).

54. Balic, A., Harcus, Y., Holland, M.J. \& Maizels, R.M. Selective maturation of dendritic cells by Nippostrongylus brasiliensis secreted proteins drives T-helper type 2 immune responses. Eur. J. Immunol. 34, 3047-3059 (2004).

55. Segura, M., Su, Z., Piccirillo, C. \& Stevenson, M.M. Impairment of dendritic cell function by excretory-secretory products: a potential mechanism for nematodes-induced immunosuppression. Eur. J. Immunol. 37, 1887-1904 (2007).

56. Cervi, L., MacDonald, A.S., Kane, C., Dzierszinski, F. \& Pearce, E.J. Dendritic cells copulsed with microbial and helminth antigens undergo modified maturation, segregate the antigens to distinct intracellular compartments, and concurrently induce microbe-specific Th1 and helminth-specific Th2 responses. J. Immunol. 172, 2016-2020 (2004).

57. Kreider, T., Anthony, R.M., Urban, J.F. Jr. \& Gause, W.C. Alternatively activated macrophages in helminth infections. Curr. Opin. Immunol. 19, 228-453 (2007)

58. Finney, C.A., Taylor, M.D., Wilson, M.S. \& Maizels, R.M. Expansion and activation of CD4+CD25+ regulatory T cells in Heligmosoides polygyrus infection. Eur. J. Immunol. 37, 1874-1886 (2007).

59. King, C.L. et al. Cytokine control of parasite-specific anergy in human lymphatic filariasis. Preferential induction of a regulatory T helper type 2 lymphocyte subset. J. Clin. Invest. 92, 1667-1673 (1993).

60. King, C.L. et al. Cytokine control of parasite-specific anergy in human urinary schistosomiasis. IL-10 modulates lymphocyte reactivity. J. Immunol. 156, 4715-4721 (1996). 
61. Mahanty, S., Ravichandran, M., Raman, U., Jayaraman, K., Kumaraswami, V. \& Nutman, T.B. Regulation of parasite antigen-driven immune responses by interleukin-10 (IL-10) and IL-12 in lymphatic filariasis. Infect. Immun. 65, 1742-1747 (1997).

62. Cooper, P.J., Mancero, T., Sandoval, C., Lovato, R., Guderian, R.H. \& Nutman, T.B. Early human infection with Onchocerca volvulus is associated with an enhanced parasite-specific cellular immune response. J. Infect. Dis. 183, 1662-1668 (2001)

63. Satoguina, J. et al. Antigen-specific T regulatory-1 cells are associated with immunosuppression in a chronic helminth infection (onchocerciasis). Microbes Infect. 4, 1291-1300 (2002).

64. Mitre, E., Chien, D. \& Nutman, T.B. CD4(+) (and not CD25+) T cells are the predominant interleukin-10-producing cells in the circulation of filariainfected patients. J. Infect. Dis. 197, 94-101 (2008).

65. Steel, C. \& Nutman, T.B. CTLA-4 in filarial infections: implications for a role in diminished T cell reactivity. J. Immunol. 170, 1930-1938 (2003).

66. Babu, S., Blauvelt, C.P., Kumaraswami, V. \& Nutman, T.B. Regulatory networks induced by live parasites impair both Th1 and Th2 pathways in patent lymphatic filariasis: implications for parasite persistence. J. Immunol. 176, 3248-3256 (2006).

67. Cooper, P.J., Mitre, E., Moncayo, A.L., Chico, M.E., Vaca, M. \& Nutman, T.B. Ascaris lumbricoides-induced interleukin-10 is not associated with atopy in school children in a rural area of the tropics. J. Infect. Dis. 197, 1333-1340 (2008)

68. Turner, J.D. et al. Intensity of intestinal infection with multiple worm species is related to regulatory cytokine output and immune hyporesponsiveness. J. Infect. Dis. 197, 1204-1212 (2008).

69. Geiger, S.M. et al. Stage-specific immune responses in human Necator americanus infection. Parasite Immunol. 29, 347-358 (2007).

70. Fujiwara, R.T. et al. Necator americanus Infection: a possible cause of altered dendritic cell differentiation and eosinophil profile in chronically infected individuals. PLoS Negl. Trop. Dis. 3, e399 (2009).

71. Geiger, S.M., Massara, C.L., Bethony, J., Soboslay, P.T. \& CorrêaOliveira, R. Cellular responses and cytokine production in post-treatment hookworm patients from an endemic area in Brazil. Clin. Exp. Immunol. 136, 334-340 (2004)

72. Keusch, G.T. Subclinical malabsorption in Thailand. I. Intestinal absorption in Thai children. Am. J. Clin. Nutr. 25, 1062-1066 (1972).

73. Gracey, M. The contaminated small bowel syndrome: pathogenesis, diagnosis, and treatment. Am. J. Clin. Nutr. 32, 234-243 (1979).

74. Fagundes-Neto, U., Viaro, T., Wehba, J., Patrício, F.R. \& Machado, N.L. Tropical enteropathy (environmental enteropathy) in early childhood: a syndrome caused by contaminated environment. J. Trop. Pediatr. 30, 204-209 (1984).

75. Haghighi, P. \& Wolf, P.L. Tropical sprue and subclinical enteropathy: a vision for the nineties. Crit. Rev. Clin. Lab. Sci. 34, 313-341 (1997)

76. Mathan, M.M. \& Mathan, V.I. Rectal mucosal morphologic abnormalities in normal subjects in southern India: a tropical colonopathy? Gut 26, 710-717 (1985).

77. Gracey, M., Suharjono, S. \& Stone, D.E. Microbial contamination of the gut: another feature of malnutrition. Am. J. Clin. Nutr. 26, 1170-1174 (1973).

78. Saltman, J. Asthma-the most common chronic disease of childhood. Am. Lung Assoc. Bull. 63, 4-6 (1977).

79. International Study of Asthma and Allergies in Childhood (ISAAC). Worldwide variation in prevalence of symptoms of asthma, allergic rhinoconjunctivitis, and atopic eczema: ISAAC. The International Study of Asthma and Allergies in Childhood (ISAAC) Steering Committee. Lancet 351, 1225-1232 (1998).

80. Cooper, P.J., Rodrigues, L.C., Cruz, A.A. \& Barreto, M. The asthma epidemic in Latin America: a public heath challenge and research opportunities. Allergy 64, 5-17 (2009).

81. Strachan, D.P. Hay fever, hygiene and household size. BMJ 25, 1259 1260 (1989).

82. von Mutius, E. Allergies, infections and the hygiene hypothesis - the epidemiological evidence. Immunobiology 212, 433-439 (2007).

83. Wilson, M.S. \& Maizels, R.M. Regulatory T cells induced by parasites and the modulation of allergic responses. Chem. Immunol. Allergy 90 , 176-195 (2006).

84. Fallon, P.G. \& Mangan, N.E. Suppression of Th2-type allergic reactions by helminth infection. Nat. Rev. Immunol. 7, 220-230 (2007).

85. Kitagaki, K. et al. Intestinal helminths protect in a murine model of asthma. J. Immunol. 177, 1628-1635 (2006).
86. Wilson, M.S., Taylor, M.D., Balic, A., Finney, C.A.M., Lamb, J.R. \& Maizels, R.M. Suppression of allergic airway inflammation by helminthinduced regulatory T cells. J. Exp. Med. 202, 1199-1212 (2006).

87. Smits, H.H. et al. The protective effect of Schistosoma mansoni infection on allergic asthma depends on the intensity and chronicity of infection. J. Allergy Clin. Immunol. 120, 932-940 (2007).

88. Reece, J.J., Siracusa, M.C. \& Scott, A.L. Innate immune responses to lung-stage helminth infection induce alternatively activated alveolar macrophages. Infect. Immun. 74, 4970-4981 (2006).

89. Reece, J.J., Siracusa, M.C., Southard, T.L., Brayton, C.F., Urban, J.F. Jr \& Scott, A.L. Hookworm-induced persistent changes to the immunological environment of the lung. Infect. Immun. 76, 3511-3524 (2008).

90. Cooper, P.J. The interactions of parasites with allergy. Curr. Opin. Allergy Clin. Immunol. 9, 29-37 (2009).

91. Kurukulaaratchy, R.J. et al. Characterization of wheezing phenotypes in the first 10 years of life. Clin. Exp. Allergy 33, 573-578 (2003).

92. Stein, R.T. \& Martinez, F.D. Asthma phenotypes in childhood: lessons from an epidemiological approach. Paediatr. Respir. Rev. 5, 155-161 (2004).

93. García-Marcos, L. et al. A different pattern of risk factors for atopic and non-atopic wheezing in 9-12-year-old children. Pediatr. Allergy Immunol. 16, 471-477 (2005)

94. Pereira, M.U. et al. Nonatopic asthma is associated with helminth infections and bronchiolitis in poor children. Eur. Respir. J. 29, 11541160 (2007).

95. Moffatt, M.F. et al. Genetic variants regulating ORMDL3 expression contribute to the risk of childhood asthma. Nature 448, 470-473 (2007).

96. Scrivener, S. et al. Independent effects of intestinal parasite infection and domestic allergen exposure on risk of wheeze in Ethiopia: a nested case-control study. Lancet 358, 1493-1499 (2001).

97. Dagoye, D. et al. Wheezing, allergy and parasite infection in children in urban and rural Ethiopia. Am. J. Resp. Crit. Care Med. 167, 1369-1373 (2003).

98. Davey, G. et al. Wheeze, allergic sensitization and geohelminth infection in Butajira, Ethiopia. Clin. Exp. Allergy 35, 301-307 (2005).

99. Leonardi-Bee, J., Pritchard, D. \& Britton, J. Asthma and current intestinal parasite infection: systematic review and meta-analysis. Am. J. Respir. Crit. Care Med. 174, 514-523 (2006).

100. Hagel, I. et al. Infection by Ascaris lumbricoides and bronchial hyper reactivity: an outstanding association in Venezuelan school children from endemic areas. Acta Trop. 103, 231-241 (2007).

101. Hunninghake, G.M. et al. Sensitization to Ascaris lumbricoides and severity of childhood asthma in Costa Rica. J. Allergy Clin. Immunol. 119, 654-661 (2007)

102. Takeuchi, H. et al. High titre of anti-Ascaris immunoglobulin E associated with bronchial asthma symptoms in 5-year-old rural Bangladeshi children. Clin. Exp. Allergy 38, 276-282 (2008).

103. Camara, A.A. et al. Risk factors for wheezing in a subtropical environment: role of respiratory viruses and allergen sensitization. $J$. Allergy Clin. Immunol. 113, 551-557 (2004).

104. da Silva, E.R. et al. Intestinal helminth infestation is associated with increased bronchial responsiveness in children. Pediatr. Pulmonol. 43, 662-665 (2008).

105. Holland, M.J., Harcus, Y.M., Riches, P.L. \& Maizels, R.M. Proteins secreted by the parasitic nematode Nippostrongylus brasiliensis act as adjuvants for Th2 responses. Eur. J. Immunol. 30, 1977-1987 (2000).

106. Mortimer, K. et al. Dose-ranging study for trials of therapeutic infection with Necator americanus in humans. Am. J. Trop. Med. Hyg. 75, 914920 (2006).

107. van den Biggelaar, A. et al. Decreased atopy in children infected with Schistosoma haematobium: a role for parasite-induced interleukin-10. Lancet 356, 1723-1727 (2000).

108. Medeiros, M. Jr. et al. Schistosoma mansoni infection is associated with a reduced course of asthma. J. Allergy Clin. Immunol. 111, 947-951 (2003)

109. Araujo, M.l et al. Impaired T helper 2 response to aeroallergen in helminth-infected patients with asthma. J. Infect. Dis. 190, 1797-1803 (2004).

110. Cooper, P.J. et al. Environmental determinants of total IgE among school children living in the rural tropics: association with geohelminth infection and effect of repeated albendazole treatments. BMC Immunol. 9, 33 (2008). 
111. Lynch, N.R. et al. Effect of anthelmintic treatment on the allergic reactivity of children in a tropical slum. J. Allergy Clin. Immunol. 92, 404-411 (1993).

112. van den Biggelaar, A.H. et al. Long-term treatment of intestinal helminths increases mite skin-test reactivity in Gabonese schoolchildren. J. Infect. Dis. 189, 892-900 (2004).

113. Cooper, P.J. et al. Impact of bimonthly treatment of geohelminth-infected children with albendazole on atopy prevalence: a cluster-randomized trial. Lancet 367, 1598-1603 (2006).

114. Lynch, N.R., Palenque, M., Hagel, I. \& DiPrisco, M.C. Clinical improvement of asthma after anthelmintic treatment in a tropical situation. Am. J. Respir. Crit. Care Med. 156, 50-54 (1997).

115. Rodrigues, L.C. et al. Early infection with Trichuris trichiura and allergen skin test reactivity in later childhood. Clin. Exp. Allergy 38, 1769-1777 (2008).

116. Beasley, R., Pekkanen, J.\& Pearce, N. Has the role of atopy in the development of asthma been over-emphasized? Pediatr. Pulmonol. S23, 149-150 (2001).

117. Penny, M.E. et al. Respiratory symptoms, asthma, exercise test spirometry, and atopy in schoolchildren from a Lima shanty town. Thorax 56, 607-612 (2001).

118. Weinmayr, G. et al. Atopic sensitization and the international variation of asthma symptom prevalence in children. Am. J. Respir. Crit. Care Med. 176, 565-574 (2007).

119. Moffatt, M.F. Genes in asthma: new genes and new ways. Curr. Opin. Allergy Clin. Immunol. 8, 411-417 (2008).

120. Xavier, R.J. \& Podolsky, D.K. Unravelling the pathogenesis of inflammatory bowel disease. Nature 448, 427-434 (2007).

121. Kugathasan, S. \& Amre, D. Inflammatory bowel disease-environmental modification and genetic determinants. Pediatr. Clin. North Am. 53, 727749 (2006).

122. Bernstein, C.N., Blanchard, J.F., Rawsthorne, P. \& Wajda, A. Epidemiology of Crohn's disease and ulcerative colitis in a central Canadian province: a population-based study. Am. J. Epidemiol. 149, 916-924 (1999).

123. Loftus, E.V. Jr Clinical epidemiology of inflammatory bowel disease: incidence, prevalence, and environmental influences. Gastroenterology 126, 1504-1517 (2004).

124. Lakatos, L. \& Lakatos, P.L. Is the incidence and prevalence of inflammatory bowel diseases increasing in Eastern Europe? Postgrad. Med. J. 82, 332-337 (2006).

125. Thia, K.T., Loftus, E.V. Jr, Sandborn, W.J. \& Yang, S.K An update on the epidemiology of inflammatory bowel disease in Asia. Am. J. Gastroenterol. 103, 3167-3182 (2008).

126. Elliott, D.E., Urban, J.F.JR., Argo, C.K. \& Weinstock, J.V. Does the failure to acquire helminthic parasites predispose to Crohn's disease? FASEB J. 14, 1848-1855 (2000).

127. Ouyang, Q. et al. The emergence of inflammatory bowel disease in the Asian Pacific region. Curr. Opin. Gastroenterol. 21, 408-413 (2005).

128. Weinstock, J.V. \& Elliott, D.E. Helminths and the IBD hygiene hypothesis. Inflamm. Bowel Dis. 15, 128-133 (2009).

129. Reardon, C., Sanchez, A., Hogaboam, C.M. \& McKay, D.M. Tapeworm infection reduces epithelial ion transport abnormalities in murine dextran sulfate sodium-induced colitis. Infect. Immun. 69, 4417-4423 (2001).

130. Khan, W.I. et al. Intestinal nematode infection ameliorates experimental colitis in mice. Infect. Immun. 70, 5931-5937 (2002).

131. Elliott, D.E. et al. Heligmosomoides polygyrus inhibits established colitis in IL-10-deficient mice. Eur. J. Immunol. 34, 2690-2698 (2004).

132. Moreels, T.G. et al. Concurrent infection with Schistosoma mansoni attenuates inflammation induced changes in colonic morphology, cytokine levels, and smooth muscle contractility of trinitrobenzene sulphonic acid induced colitis in rats. Gut 53, 99-107 (2004).

133. Fox, J.G. et al. Concurrent enteric helminth infection modulates inflammation and gastric immune responses and reduces helicobacterinduced gastric atrophy. Nat. Med. 6, 536-542 (2000).

134. Chen, C.C., Louie, S., McCormick, B., Walker, W.A. \& Shi, H.N. Concurrent infection with an intestinal helminth parasite impairs host resistance to enteric Citrobacter rodentium and enhances Citrobacterinduced colitis in mice. Infect. Immun. 73, 5468-5481 (2005).

135. Setiawan, T. et al. Heligmosomoides polygyrus promotes regulatory Tcell cytokine production in the murine normal distal intestine. Infect. Immun. 75, 4655-4663 (2007).
136. Raine, T., Zaccone, P., Dunne, D.W. \& Cooke, A. Can helminth antigens be exploited therapeutically to downregulate pathological Th1 responses? Curr. Opin. Investig. Drugs 5, 1184-1191 (2004).

137. Sutton, T.L. et al. Anti-Inflammatory mechanisms of enteric Heligmosomoides polygyrus infection against trinitrobenzene sulfonic acid-induced colitis in a murine model. Infect. Immun. 76, 4772-4782 (2008).

138. Elliott, D.E. et al. Colonization with Heligmosomoides polygyrus suppresses mucosal IL-17 production. J. Immunol. 181, 2414-2419 (2008).

139. Weng, M. et al. Alternatively activated macrophages in intestinal helminth infection: effects on concurrent bacterial colitis. J. Immunol. 179, 47214731 (2007).

140. Chen, C.C., Louie, S., McCormick, B.A., Walker, W.A. \& Shi, H.N. Helminth-primed dendritic cells alter the host response to enteric bacterial infection. J. Immunol. 176, 472-483 (2006).

141. Ince, M.N. et al. Heligmosomoides polygyrus induces TLR4 on murine mucosal $T$ cells that produce TGFbeta after lipopolysaccharide stimulation. J. Immunol. 176, 726-729 (2006).

142. Ilic, N., Colic, M., Gruden-movsesijan, A., Majstorovic, I., Vasilev, S. \& Sofronic-Milosavljevic, L.J. Characterization of rat bone marrow dendritic cells initially primed by Trichinella spiralis antigens. Parasite Immunol. 30, 491-495 (2008).

143. Elliott, D.E. et al. Exposure to schistosome eggs protects mice from TNBS-induced colitis. Am. J. Physiol. Gastrointest. Liver Physiol. 284, G385-G391 (2003).

144. Ruyssers, N.E. et al. Therapeutic potential of helminth soluble proteins I TNBS-induced colitis in mice. Inflamm. Bowel Dis. 15, 1-10 (2009).

145. Hunter, M.M., Wang, A. \& McKay, D.M. Helminth infection enhances disease in a murine Th2 model of colitis. Gastroenterology 132, 13201330 (2007)

146. Summers, R.W. et al. Trichuris suis seems to be safe and possibly effective in the treatment of inflammatory bowel disease. Am. J. Gastroenterol. 98, 2034-2041 (2003).

147. Summers, R.W. et al. Trichuris suis therapy for active ulcerative colitis: a randomized trial. Gastroenterology 128, 828-832 (2005).

148. Summers, R.W., Elliott, D.E., Urban, J.F. Jr, Thompson, R. \& Weinstock, J.V. Trichuris suis therapy in Crohn's disease. Gut 54, 87-90 (2005).

149. Kradin, R.L., Badizadegan, K., Auluck, P., Korezenik, J. \& Lauwers, G.Y. Itraogenic Trichuris suis infection in a patient with Crohn disease. Arch. Pathol. Lab. Med. 130, 718-720 (2006).

150. Van Kruiningen, H.J. \& West, A.B. latrogenic Trichuris suis infection. Arch. Pathol. Lab. Med. 131, 180 (2007).

151. Reddy, A. \& Fried, B. An update on the use of helminths to treat Crohn's and other autoimmunune diseases. Parasitol. Res. 104, 217-221 (2009).

152. Cheng, A.C., McDonald, J.R. \& Thielman, N.M. Infectious diarrhea in developed and developing countries. J. Clin. Gastroenterol. 39, $757-$ 773 (2005).

153. Gilles, H.M. Soil-transmitted helminths (geohelminths). In Manson's Tropical Diseases (Cook, G.A) 1369-1412 (W.B. Saunders, London, 1996).

154. Cooper, P.J., Sandoval, C., Chico, M.E. \& Griffin, G.E. Geohelminth parasites protect against severe inflammatory diarrhoea. Trans. R. Soc. Trop. Med. Hyg. 97, 519-521 (2003).

155. Mansfield, L.S. \& Urban, J.F. Jr. The pathogenesis of necrotic proliferative colitis in swine is linked to whipworm induced suppression of mucosal immunity to resident bacteria. Vet. Immunol. Immunopathol. 50, 1-17 (1996).

156. Mansfield, L.S. et al. Enhancement of disease and pathology by synergy of Trichuris suis and Campylobacter jejuni in the colon of immunologically naive swine. Am. J. Trop. Med. Hyg. 68, 70-80 (2003).

157. Abner, S.R. et al. Response of intestinal epithelial cells to Trichuris suis excretory-secretory products and the influence on Campylobacter jejuni invasion under in vitro conditions. J. Parasitol. 88, 738-745 (2002).

158. Elias, D., Britton, S., Kassu, A. \& Akuffo, H. Chronic helminth infections may negatively influence immunity against tuberculosis and other diseases of public health importance. Expert Rev. Anti Infect. Ther. 5, 475-484 (2007).

159. Brown, M., Mawa, P.A., Kaleebu, P. \& Elliott, A.M. Helminths and HIV infection: epidemiological observations on immunological hypotheses. Parasite Immunol. 28, 613-623 (2006). 
160. Borkow, G. \& Bentwich, Z. HIV and helminth co-infection: is deworming necessary? Parasite Immunol. 28, 605-612 (2006).

161. Nacher, M. Worms and malaria: noisy nuisances and silent benefits. Parasite Immunol. 24, 391-393 (2002).

162. O'Neal, S.E. et al. Influence of helminth infections on the clinical course of and immune response to Leishmania braziliensis cutaneous leishmaniasis. J. Infect. Dis. 195, 142-148 (2007).

163. Rodríguez-Sosa, M. et al. Acute cysticercosis favours rapid and more severe lesions caused by Leishmania major and Leishmania mexicana infection, a role for alternatively activated macrophages. Cell Immunol. 242, 61-71 (2006).

164. Geiger, S.M. Immuno-epidemiology of Schistosoma mansoni infections in endemic populations co-infected with soil-transmitted helminths: present knowledge, challenges, and the need for further studies. Acta Trop. 108, 118-123 (2008).

165. Curry, A.J. et al. Evidence that cytokine-mediated immune interactions induced by Schistosoma mansoni alter disease outcome in mice concurrently infected with Trichuris muris. J. Exp. Med. 181, 769-774 (1995).

166. Bickle, Q.D., Solum, J. \& Helmby, H. Chronic intestinal nematode infection exacerbates experimental Schistosoma mansoni infection. Infect. Immun. 76, 5802-5809 (2008).

167. Bazzone, L.E. et al. Coinfection with the intestinal nematode Heligmosomoides polygyrus markedly reduces hepatic egg-induced immunopathology and proinflammatory cytokines in mouse models of severe schistosomiasis. Infect. Immun. 76, 5164-5172 (2008).

168. John, T.J. \& Jayabal, P. Oral polio vaccination of children in the tropics. I. The poor seroconversion rates and the absence of viral interference. Am. J. Epidemiol. 96, 263-269 (1972).

169. Patriarca, P.A., Wright, P.F. \& John, T.J. Factors affecting the immunogenicity of oral poliovirus vaccine in developing countries: review. Rev. Infect. Dis. 13, 926-939 (1991).

170. Lanata, C.F. et al. Safety, immunogenicity, and protective efficacy of one and three doses of the tetravalent rhesus rotavirus vaccine in infants in Lima, Peru. J. Infect. Dis. 174, 268-275 (1996).

171. Linhares, A.C. et al. Immunogenicity, safety and efficacy of tetravalent rhesus-human, reassortant rotavirus vaccine in Belém, Brazil. Bull. World Health Organ. 74, 491-500 (1996).
172. Su-Arehawaratana, P. et al. Safety and immunogenicity of different immunization regimens of CVD 103-HgR live oral cholera vaccine in soldiers and civilians in Thailand. J. Infect. Dis. 165, 1042-1048 (1992).

173. Suharyono et al. Safety and immunogenicity of single-dose live oral cholera vaccine CVD 103-HgR in 5-9-year-old Indonesian children. Lancet 340, 689-694 (1992).

174. Glass, R.I. et al. Rotavirus vaccines: current prospects and future challenges. Lancet 368, 323-332 (2006).

175. Linhares, A.C. \& Bresee, J.S. Rotavirus vaccines and vaccination in Latin America. Rev. Panam. Salud Publica 8, 305-331 (2000).

176. Pérez-Schael, I. et al. Efficacy of the rhesus rotavirus-based quadrivalent vaccine in infants and young children in Venezuela. N Engl J Med 337, 1181-1187 (1997).

177. Grassly, N.C. et al. Protective efficacy of a monovalent oral type 1 poliovirus vaccine: a case-control study. Lancet 369, 1356-1362 (2007).

178. Salinas, B. et al. Evaluation of safety, immunogenicity and efficacy of an attenuated rotavirus vaccine, RIX4414: a randomized, placebocontrolled trial in Latin American infants. Pediatr. Infect. Dis. J. 24, 807816 (2005).

179. Steele, A.D. et al. Co-administration study in South African infants of a live-attenuated oral human rotavirus vaccine (RIX4414) and poliovirus vaccines. Vaccine (2008); e-pub ahead of print.

180. Cooper, P.J. et al. Albendazole treatment of children with ascariasis enhances the vibriocidal antibody response to the live attenuated oral cholera vaccine CVD 103-HgR. J. Infect. Dis. 182, 1199-1206 (2000).

181. Urban, J.F. Jr et al. Infection with parasitic nematodes confounds vaccination efficacy. Vet. Parasitol. 148, 14-20 (2007).

182. Pit, D.S., Polderman, A.M., Schulz-Key, H. \& Soboslay, P.T. Prenatal immune priming with helminth infections: parasite-specific cellular reactivity and Th1 and Th2 cytokine responses in neonates. Allergy 55, 732-739 (2000)

183. Guadalupe, I. et al. Evidence of intrauterine sensitization to Ascaris lumbricoides infection in newborns of infected mothers. J. Infect. Dis. (2008) (in press).

184. Harnett, W. \& Harnett, M.H. Filarial nematode secreted product ES-62 is an anti-inflammatory agent: therapeutic potential of small molecule derivatives and ES-62 peptide mimetics. Clin. Exp. Pharm. Physiol. 33, 511-518 (2006). 